\title{
Epistemic Normativity and the Justification-Excuse Distinction
}

\section{Introduction}

The distinction between justifications and excuses is a popular topic in contemporary epistemology. It figures prominently in debates about norms of belief, assertion and practical reason, and debates about radically deceived subjects. Why is this? Here is one explanation, due to Littlejohn:

If we had a better understanding of the difference between justificatory and excusatory defenses, we'd have a better understanding of the significance of the intuitions that shape the internalism-externalism debate (Littlejohn forthcoming, p.1).

Littlejohn's claim gets at a central point of interest. Excuses help (some) externalists account for and explain away intuitions that pose problems for their views about justification. For example, excuses help explain away intuitions that certain cases of noncriticizable or blameless $\Phi$-ing are cases of justified $\Phi$-ing. ${ }^{1}$ When it comes to evaluating belief, here are two important cases:

GETTIER: Ed comes downstairs in the morning and checks the time. He checks a clock that he knows to be generally reliable. However, the clock happened to stop exactly twenty-four hours ago. He forms the perfectly blameless and true belief that it is 8am. But Ed does not know that it is 8am.

BRAIN IN A VAT (BIV): Dave has recently been envatted and hooked up to an experience machine. He is the internal duplicate of an ordinary, epistemically blameless person. He continues to believe he has hands because it looks to him just like he has hands. But Dave does not know that he has hands.

According to externalists who understand epistemic justification in terms of a knowledge norm of belief, for example, these agents violate the norm of belief and do not count as justified. According to many, there is a tension between this result and Ed and Dave's blamelessness. But in addition to epistemic justifications, there are epistemic excuses, and there is room to understand cases like GETTIER and BIV as cases of agents having an excuse as opposed to a justification. This way, proponents of the knowledge norm argue there is no tension between withholding attributions of justified belief and

\footnotetext{
${ }^{1}$ Of course, problems for externalists in this area are not restricted to intuitions about cases. There are also theoretical considerations that augment such intuitions. It is also worth noting that the tendency to treat blamelessness as central to justification is found predominantly in epistemological internalists who understand justified belief in deontological terms, such as believing in accordance with epistemic duties, permissions, or obligations.
} 
acknowledging Ed and Dave's blamelessness. According to Littlejohn, this is a big part of the "better understanding of the significance of the intuitions that shape the internalism-externalism debate." It is important, then, to get clear on what makes this understanding better. Is it because it latches onto an independently motivated conception of the structure of epistemic normativity? Or is it because such an understanding puts certain externalists in the clear on some problematic cases?

The qualification "certain externalists" is important. Indeed, GETTIER and BIV are often considered cases of justified belief by both internalists and externalists such as Goldman (1979), Dretske (1981), Burge (2003), and Graham (2012). Littlejohn's point is that excuses are important when it comes to defending a particularly strong form of externalism - namely, one that understands justified belief in terms of compliance with a factive norm. I will not be getting into the question of whether strong externalism is unnecessarily strong. Instead, I will be examining an important issue for such a view, and arguing that strong externalism has a lot going for it vis-à-vis this issue. ${ }^{2}$

In recent work, Williamson (forthcoming) and Littlejohn (forthcoming) have each developed their own frameworks according to which certain appeals to excuses (in defense of various externalist theses) come out looking principled and well motivated. In other words, they provide accounts of how the justification-excuse distinction fits into an independently motivated conception of the structure of epistemic normativity. Given the importance of this issue in debates about epistemic norms, and the internalismexternalism debate generally, these recent developments deserve careful attention.

In this paper, I center discussion largely on a key idea in Williamson's framework. Williamson understands excuses in terms of the positive standing that comes from acting in a way that someone who is disposed to comply with a given norm would act. As I explain, this idea is interesting because it appears to offer resources for dealing with Gerken's (2011) influential claim that the "excuse maneuver" is ad hoc. That said, I formulate and examine an additional objection to the so-called excuse maneuver. I call it the "excuses are not enough" objection. Dealing with this objection generates pressure in two directions: one is to show that excuses are a positive enough normative standing to

\footnotetext{
${ }^{2}$ Strong externalism has a variety of prominent proponents, such as Adler (2002), Huemer (2007), Littlejohn (2012), Sutton (2005), and Williamson (2000; 2013). It is also worth noting that everyone needs to make at least some kind of distinction when it comes to cases like GETTIER and BIV and ordinary or "good" cases of well-formed belief. For example, consider Goldman's distinction between "strong" and "weak" justification (Goldman 1988). This paper examines and ultimately defends the strong externalist approach of drawing such a distinction in terms of justifications and excuses. Although I won't argue as much, the view I develop in this paper may provide resources for any theory of justification that struggles with cases like GETTIER and BIV. For instance, rather than resorting to actual worlds reliabilism, normal worlds reliabilism, distinctions between strong and weak justification, and so on, proponents of various theories may simply want to apply the justification-excuse distinction in such cases, in support of their theory of justification. Thanks to an anonymous reviewer and [removed] for suggestions along these lines.
} 
help strong externalists with cases like GETTIER and BIV; the other is to do so in a way that does not lead back to Gerken's initial objection. In a final section, I put forward a positive proposal. Perhaps surprisingly, the proposal draws on recent virtue epistemology. The basic idea is that epistemic excuses (as opposed to justifications) should be understood in terms of the manifestation of certain cognitive abilities or competences. The result is a view about the nature of epistemic excuses that can deal with both sources of pressure.

\section{Gerken on Primary and Secondary Propriety}

In an early discussion of the norm of assertion, DeRose (2002) defends a knowledge norm of assertion against the worry that it delivers the wrong results in certain cases of blameless assertions. He appeals to a distinction between two senses of propriety. Primary propriety requires compliance with a norm. Secondary propriety requires something less. In particular, it requires that an agent reasonably believe they comply with the relevant norm.

As a way of understanding the justification-excuse distinction, the idea would be that agents who meet the requirements of primary propriety are justified. Agents who merely meet the requirements of secondary propriety have an excuse. It's because they meet these requirements that they count as having an excuse for failing to meet the requirements of primary propriety. That is to say, the fact that they reasonably believe themselves to comply with the relevant norm means they deserve an excuse for $\Phi$-ing, even though they are not justified in $\Phi$-ing. ${ }^{3}$ This provides DeRose with resources for explaining away intuitions that certain cases of non-criticizable or blameless $\Phi$-ing are cases of justified $\Phi$-ing.

Gerken (2011) is not convinced. Transposing to the debate about the so-called norm of action, he argues that proponents of a knowledge norm of action make an analogous "excuse maneuver." $\mathrm{He}$ argues that the maneuver fails to apply to a subset of the cases that are counterexamples to the knowledge norm. In particular, he claims that there are cases of agents who fail to comply with the knowledge norm, are not criticizable, and who are incapable of meeting the requirements of secondary propriety. Gerken's main claim is that secondary propriety places implausible demands on the conceptual

\footnotetext{
${ }^{3}$ DeRose (2002) does not explicitly link secondary propriety to excuse. He simply talks about secondary propriety (and for an interestingly short period of time, given that he is heavily cited for it). Lackey (2007), who challenges secondary propriety, does not seem to think of it as being explicitly connected to excuse either. Indeed, she appeals to excuses as part of her argument against DeRose's distinction. Meanwhile, Gerken (2007) and Littlejohn (forthcoming) both see tight connections between secondary propriety and excuse.

${ }^{4}$ One reason to think that there is some structural symmetry here is assertion is an act (a speech act). See Gerken (2012). To be sure, the relationship between norms of action and norm of assertion is debated.
} 
capacities of agents in these cases. Since they do not meet the requirements of secondary propriety, Gerken argues, the only reason to attribute excuses to them (so far as we have been told) is to save the knowledge norm.

The point is not that there are cases in which non-complying but non-criticizable agents simply happen not to reasonably believe themselves to comply with the relevant norm. Rather, Gerken appeals to cases in which the agent is incapable of having the relevant higher-order thought. Consider cases of small children, or perhaps cases of higher animals like chimpanzees. It is easy to imagine a young enough child mistakenly but noncriticizably acting on the belief that there is an apple on the table in front of them (say, when what they see is a realistic fake). Small children arguably do not have the conceptual capacities for entertaining the thought: "I know there is an apple on the table." If that is the case, they cannot meet the requirements of secondary propriety. That is, they cannot reasonably take themselves to comply with a knowledge norm of action. So the notion of secondary propriety does not help explain blameless norm violation in this sort of case. In other words, as far as DeRose's notion of secondary propriety tells us, we do not have a principled reason merely to excuse the agents in the cases. According to Gerken, the excuse maneuver seems ad hoc.

A natural response is to weaken the requirements of secondary propriety. For example, rather than demanding that the agent have some sort of doxastic justification for the belief that they comply with the knowledge norm (i.e. "reasonably believe"), we might demand that they have propositional justification with respect to the proposition: "I know that p". Gerken provides compelling reasons to think that such a move is dialectically ineffective. That is, making such a move ultimately renders it unclear why an agent who enjoys this kind of propositional justification vis-à-vis the proposition that they comply with the knowledge norm deserves an excuse. An excuse is usually something we attribute to an agent because they have done something commendable despite their unfortunate circumstances. Propositional justification just doesn't have enough to do with the agent to ground the sort of merit we usually confer on someone by excusing them. I'll return to this relationship between merits of the agent and excuses below.

Gerken's objection to DeRose's appeal to secondary propriety as a way of responding to objections from blameless norm violation looks compelling. ${ }^{6}$ But it raises some important questions. Moreover, the primary-secondary propriety distinction is not the only

\footnotetext{
${ }^{5}$ Gerken appeals to the so-called "false belief test". He claims that a good explanation of the fact that small children fail the false belief test is that they lack the concept of belief. Interesting questions aside as to whether children may acquire the concept of knowledge before that of belief, he takes this as evidence in support of the claim that such children lack the higher-order ability to take themselves to enjoy other epistemic states, like knowledge, with respect to a proposition $p$.

${ }^{6}$ There may of course be other responses to Gerken's objection. In what follows, I am interested in Williamson's view because it appears to avoid the objection altogether.
} 
framework available for constructing a principled theory of excuses in epistemology. For example, Williamson (forthcoming) has a different framework, and it inspires a way to avoid Gerken's objection. As we will see, it also facilitates discussion of some more general issues with Gerken's objection.

\section{Derivative Norms Framework}

Williamson takes a step back from epistemology and makes some general normative distinctions. The idea is to return to epistemology with those independently motivated distinctions in hand. He starts by claiming that, "a given norm typically generates various derivative norms" (Williamson forthcoming, p. 6). More specifically, he claims that there are two types of norm that derive from a given norm, "N". The first of these requires an agent to be the kind of person who is disposed to comply with $\mathrm{N}$ (call this "DN"). The basic idea is intuitive enough. As Williamson puts it with respect to a norm of keeping one's promises, "[i]f it is bad not to keep a promise, then there is also something bad about not being generally disposed to keep one's promises [...]" (Williamson

forthcoming, p.9). It is important to note, however, that the normative force of this sort of derivative norm is in some sense weaker than the norm from which it derives. We can illustrate with legal norms. For example, if one fails to comply with a legal norm N, one breaks the law. But failing to comply with the derivative norm telling you to be the sort of person who is normally disposed to comply with $\mathrm{N}$ does not amount to breaking the law. ${ }^{7}$ As Williamson puts it, “...[F]or accidental reasons, one might still never break the law, at least in a non-totalitarian state where lacking a law-abiding disposition is not itself illegal" (Williamson, forthcoming, p. 6)).

The second of Williamson's derivative norms requires agents to do what a person who is disposed to comply with $\mathrm{N}$ would do under the relevant circumstances (call this "ODN", where "O" stands for "occurrent"). Continuing with the promise-keeping example, Williamson suggests that if there is something bad about not being generally disposed to keep one's promises, then there is also "something bad about not doing what someone so disposed would do" (Williamson forthcoming, p.9). Again, taking into account

\footnotetext{
${ }^{7}$ Note that whatever kind of norm this derivative norm is, it is certainly not a legal norm. Perhaps this is Williamson's point. But one might also ask the following question. Does the fact that this so-called "derivative norm" fails even to belong to the same normative domain as the primary norm undermine the idea that it derives from the primary norm? I am not entirely sure. But here is one way of understanding "derivative" which seems to avoid the worry. The idea is to understand "derivative" in terms of an explanatory connection. That is, a given norm derives from a norm $\mathrm{N}$ in the sense that the positive status associated with compliance with it is to be explained in terms of the positive status associated with compliance with N. On this approach, the fact that it is good to be a law-abiding person-though not necessary for compliance with the law itself - is nonetheless explained in terms of the fact that it is good not to break the law. I'll set further discussion of this question to one side here.
} 
Williamson's claim that these derivate norms do not have the same normative force as the norms that generate them, this seems intuitive enough. ${ }^{8}$

From the basic idea that norms governing our actions and attitudes imply secondary and tertiary norms pertaining to the types of people we ought to be, or act like, Williamson claims to be able to provide a well-motivated account of the justification-excuse distinction. In particular, agents have excuses for violating a given norm $\mathrm{N}$ when they fail to comply with $\mathrm{N}$ but comply with ODN. And they have much better excuses when, despite failing to comply with $\mathrm{N}$, they comply with ODN and DN (more on this next section). That is, when agents act as agents who are disposed to comply with the relevant norm, they have an excuse for failing to comply with that norm. And, they have an even better excuse when, in addition to that, they are someone who is disposed to comply with the relevant norm. The reason compliance with ODN and DN cannot give one the full normative status of justification when one violates $\mathrm{N}$ is because the normative status of so doing is itself merely derivative from $\mathrm{N}$. Justification requires compliance with $\mathrm{N}$. Concerning problematic cases for strong externalists about the norm of belief like GETTIER and BIV, for example, Williamson's framework allows strong externalists to reserve the normative status of justification for agents who comply with $\mathrm{N}$, while attributing a derivative normative status that accounts for the intuition that the agent is completely blameless or non-criticizable. For example, while the BIV does not know he has hands, and therefore violates the knowledge norm of belief, he does act just like someone normally disposed to comply with the norm of belief. So, on the Derivative Norms Framework, he deserves an excuse.

Importantly, Williamson has resources for avoiding Gerken's objection to the primarysecondary propriety distinction. ${ }^{9}$ He has resources in at least two different ways. Firstly, Williamson does not use the framework to provide a set of necessary conditions on excuses. ${ }^{10}$ As such, challenging the framework in the way that Gerken challenges DeRose - by way of a counterexample - would seem to be misguided. Of course, Gerken might insist that if the framework does not offer a set of necessary conditions on excuse, it cannot help with the basic problem afflicting the excuse maneuver in the first place.

\footnotetext{
${ }^{8}$ It is not hard to imagine someone taking issue with these sweeping claims about the existence of norms such as DN and ODN. But this is one reason why it is important to keep in mind that they are relatively weak norms. Moreover, I think it is fair to approach these claims in a somewhat loose or deflationary way, and I can do so without compromising the overall argument of this paper. I regard what Williamson is doing here less as making robust theoretical claims than as offering a codified way of articulating the sorts of evaluations ordinary people find natural to make, and then drawing some fruitful conclusions.

${ }^{9}$ To be clear, Williamson does not himself address Gerken's objection to DeRose. I am simply taking Williamson's view and applying it to Gerken's objection.

${ }^{10}$ Williamson points out in a footnote: "I am not suggesting that all excuses are of the kind described. That one was distraught with grief is an excuse of a quite different kind. Excuses are inexhaustibly various; one should not expect a neat taxonomy" (fn. 6). Littlejohn (forthcoming) is also sensitive to the idea that excuses are a "motley bunch".
} 
The idea would be that this is a minimal condition on providing a general theory with which to classify specific cases. This may or may not be a reasonable demand. The issue is complicated, and I return to it below. For now, note, secondly, that even if Williamson's framework were a story about what is necessary and/or sufficient for deserving an excuse, it inspires a way to avoid Gerken's objection. This is because it classifies cases as cases of excuse without appealing to the higher-order thoughts that are the target of Gerken's objection. Instead of making claims about agents reasonably believing themselves to comply with a norm, the framework employs the notion of derivative norms governing agents' characters or dispositions. I think this is its key insight - the shift from a focus on reasonable belief to a focus on the dispositions of agents to act or be like agents who are disposed to comply with the primary norm of a given domain. Small children seem capable of complying with ODN. Thus, this insight provides a way to advance the debate beyond Gerken's objection. ${ }^{11}$

\section{Excuse as a Positive Normative Standing}

All of this said, there is an important further objection to consider. A further objection is that the strong externalist's appeal to excuses is unsatisfying in a different way.

"Deserving an excuse" is just too weak or negative sounding as a defense of agents in the important cases. For example, the BIV enjoys something more than a mere excuse for believing as he does. After all, the thought goes, he has done everything right from his first person perspective, behaved with impeccable epistemic responsibility, etc. ${ }^{12}$ Call this the "excuses are not enough" objection, or ENE for short.

\footnotetext{
${ }^{11}$ An anonymous referee points out another potential advantage of this shift. It arises in the context of a question about the specific kind of criticism excuses address. When we hold agents responsible for wrongdoing, a prominent view is that we hold them responsible for not showing de re concern for what is of normative significance. That is, we hold them responsible for not showing the right concern for what is in fact normatively significant, as opposed to what they take to be normatively significant, as such. A prominent source of motivation for this view is the fetishism charge directed against externalist accounts of moral motivation (Arpaly 2002). The plausibility of this position may further support the shift away from DeRose's approach. That is, it seems to speak against understanding excuses in terms of what agents reasonably believe, since doing so seems to go hand in hand with a de dicto reading of what makes an agent responsible for $\Phi$-ing in the first place (since it seems to understand excuse from wrongdoing in terms of what the agent takes to be normatively significant). Meanwhile, on the approach I'll be advocating, we excuse agents for doing what the person normally disposed to comply with $\mathrm{N}$ does. The thought is that this fits better with a de re reading of what makes an agent responsible for $\Phi$-ing in the first place. After all, we are talking directly in terms of a primary norm N, and spelling out excuses in terms of compliance with norms that derive from it. Thanks to the anonymous referee for this suggestion.

${ }^{12}$ What the BIV does right is not limited to meeting internalist conditions. The BIV also meets various more traditional externalist conditions, such as forming beliefs in a way that would have been objectively truth-conducive in the BIV's normal environment. As such, the issue need not merely be about epistemic responsibility. Those sympathetic to a normal worlds reliabilist way of spelling out objective truthconducive belief formation will have further things to say about the "excuses are not enough" objection.
} 
To get a sense of the idea that there is something negative or inferior about excuses as opposed to justifications, consider what Marcia Baron (2005) says about the comparative value of moral excuses and justifications:

That justifications and excuses are not on a par, morally, is uncontroversial. One does not want to be excused unless an excuse is called for (or unless the only alternative is to be punished). For example, if a colleague says to me, 'Of course we could hardly have expected you to do X, when you had just given birth a few weeks earlier, so no one blames you,' and I believe that in fact it was not my job to do X, period, I will not be entirely happy to be told that I am excused. I will be tempted to set the record straight: $X$ was someone else's responsibility, not mine. I did nothing wrong at all (Baron 2005, p.390).

There are of course important differences between Baron's example and the BIV. For one thing, by stipulation, the BIV does something wrong. He forms systematically false beliefs. But when the externalist tells us that the BIV has an excuse for believing falsely (or without knowledge), ENE says that this is unsatisfying, if not for the same reason as in Baron's example, then for something very similar. ${ }^{13}$

This is a reiteration of the objection to strong externalism in the background of our general discussion. Namely, it is a reiteration of the objection from cases of blameless or non-criticizable norm violation. Above, I said the strong externalist needs to explain away intuitions that certain cases of non-criticizable or blameless $\Phi$-ing are cases of justified $\Phi$-ing. ENE effectively adds that a good response to this objection must identify a standing that falls short of "justified" but that still seems positive enough to account for our positive reaction to these cases.

On the face of it, as should already be clear, the Derivative Norms Framework has resources for dealing with this objection, too. By connecting excuses to derivative norms, compliance with which reflects a kind of creditworthiness or praiseworthiness, it explains why certain agents deserve excuses in a way that highlights how excuses can be a much more positive or credit-implying sort of defense than one might have thought. Indeed, Williamson claims that all the standard commendable things usually said about the BIV can be understood in terms of compliance with ODN (Williamson forthcoming, p.18). The aim of casting excuses in a more positive light also shows up (in an even more pronounced way) in Littlejohn's recent work on excuses. For example, Littlejohn says

\footnotetext{
${ }^{13}$ The appeal to Baron here is not intended to suggest that she would agree with the approach to excuses advocated in this paper. Baron endorses the Kantian idea that all genuinely normative appraisal focuses on the quality of the agent's will, and the way it is exercised. As such she would take issue with the appeal to excuses as a way of promoting strong externalism in epistemology. Thanks to an anonymous referee for pressing this point.
} 
things like, “...rationality is quite often a sign of excuse, not justification” (Littlejohn forthcoming, p.21 italics in original). ${ }^{14}$

But things are a bit more complicated than this. Someone sympathetic to ENE can respond to this line of thought in the following sort of way. They can argue that explaining why the BIV deserves an excuse in terms of the BIV's compliance with ODN is not enough to account for ENE. The problem is that compliance with ODN is the sort of thing that can happen by chance. One can merely happen to act as a person normally disposed to comply with $\mathrm{N}$ would have in a given situation. To see why this is problematic in the present context, consider the following scenario. Imagine that Bill has promised to give you some money. Unbeknownst to Bill, you and Mary are perfectly disguised as one another. Bill gives Mary the money, thinking she is you. Bill violates N ("keep your promises"), but does what a person normally disposed to comply with $\mathrm{N}$ would do (thus, complies with ODN). However, imagine that in this situation Bill simply gives Mary the money because it suits him. Irrespectively of the promise, that is just what Bill happens to feel like doing. ${ }^{15} \mathrm{He}$ complies with ODN, but in such a way that seems irrelevant to the question of whether he deserves any positive sort of standing for doing so. Presumably this is because the fact that Bill complies with ODN-while that may itself be a good thing - has nothing to do with Bill's dispositions vis-à-vis the norm of promise keeping. Bill merely happens to comply with ODN because that particular course of action suits him. ${ }^{16}$

To explain why deserving an excuse can be a positive enough normative standing, it looks like we need to talk about more than mere compliance with ODN. For example, we might focus on DN in addition to ODN. To see how this might help, imagine that in a given situation Bill does what a person normally disposed to comply with $\mathrm{N}$ would have done. Moreover, imagine that Bill is that kind of person, and perhaps even does what he does because he is that kind of person. This would seem to be a highly positive sort of thing. Indeed, as I have noted, Williamson himself says that "compliance with ODN is usually a much better excuse for violating $\mathrm{N}$ if one also complies with DN" (p.10). So, perhaps this is a way of dealing with ENE.

We should note right away that compliance with DN is obviously not always what is involved in deserving an excuse. For one thing, this is because compliance with DN is a diachronic matter. Whether one complies with a norm telling one to be a kind of person

\footnotetext{
${ }^{14}$ Littlejohn continues: "It is a sign of excuse because an excuse would often be out of order if the agent's actions and attitudes weren't rational responses to the apparent reasons, responses that showed the subject to be an excellent processor of reasons, albeit an imperfect detector of them" (Littlejohn forthcoming, p.21).

${ }^{15}$ This is an adaption of an example Williamson uses in a different context.

${ }^{16}$ The point is similar to Gerken's critique of appealing to mere propositional justification in a weakened version of the requirements of secondary propriety (see Section One).
} 
is not a matter that can be settled synchronically, by considering a particular time-slice of that person. Being a kind of person is a temporal matter. For example, it seems to involve highly stable dispositions to behave in certain ways. So, if compliance with DN requires one to be a kind of person, that means one only complies with DN if one has had the relevant characteristics at to-be-specified times $\mathrm{t} 1, \mathrm{t} 2 \ldots \mathrm{tn}$ in the past, and will have the relevant characteristics at to-be-specified times $\mathrm{t} 1$ and $\mathrm{t} 2 \ldots \mathrm{tn}$ in the future. There are cases of agents deserving an excuse who do not meet these requirements. For example, imagine a person who has just begun being a lot like a promise keeper without yet fully counting as one. Imagine they are a reforming promise breaker, say. Surely this person could be excused for violating the promise keeping norm when, for example, they do just what the promise keeper would have done in a given situation, yet violate the norm of promise keeping.

Of course, given that Williamson is not offering a set of necessary conditions on excuses, he may or may not find these observations problematic. However, the issue of whether we ought to provide necessary conditions on excuse is something I would like to remain as neutral as possible on. So, it is important to point out the following. The more cases we consider, the more it looks like the appeal to dispositions of agents handles particularly problematic cases (the ones that opponents of strong externalism are interested in) in a way that is quite specific to those cases. For example, we have just seen that the Derivative Norms Framework (modified so that it makes a central role for DN) does not apply to the reforming promise breaker. And insofar as that is because of diachronic considerations, we might think the approach is equally inapplicable to Gerken's small children (more on this below). The approach seems even less applicable to well-known cases such as the brainwashed person, or the recent stroke victim. ${ }^{17}$ None of these agents are in the market for compliance with anything like DN. And yet, many will find it plausible to think of them as agents who are at least in the market for an excuse in a given situation. $^{18}$

So, something like Gerken's ad hocery objection continues to loom in the background. To put it one way, we still face pressure in two competing directions. On one hand, there is pressure to demonstrate that excuses are a positive enough normative standing. And on this score, there is a case to be made that appealing to mere compliance with ODN is not enough. But once we add further features to our explanation of why at least some excuses count as a positive enough standing - for example, because of compliance with DN as

\footnotetext{
${ }^{17}$ Examples of appeals these sorts of cases can be found in Bonjour (2002), Cohen and Comesaña (2013), Lackey (2007), Madison (2014).

${ }^{18}$ Of course, we can also do what Littlejohn does and draw a further distinction between excuses and exemptions in order to classify some of these cases in a principled way. I return to this feature of Littlejohn's approach below (fn. 25). However, even with that distinction on the table, it is not clear where to fit the reforming promise breaker or the case of small children. This is because it is not clear that these are cases of exemption.
} 
well-we see that this sort of explanation applies in a very limited range of cases. Indeed, it seems specific to the sort of case that opponents of strong externalism are inclined to classify as a case of justification. If that is right, then the strong externalist plea for excuses is starting to look ad hoc all over again. We are still some distance from settling the issue by showing how excuses are a natural way to defend agents in the contested cases in light of a general, principled framework. ${ }^{19}$

All of this said, in the next section I want to offer a potential way forward. An alternative approach to dealing with ENE is to simply beef up what is involved in complying with ODN. The idea is to build into the notion of compliance with ODN - that is, compliance with a norm that tells agents to do what a person normally disposed to comply with $\mathrm{N}$ would do - that this is the sort of thing that does not happen accidentally. I will argue that we can thereby deal with ENE while explaining a satisfying range of cases. I will look at a way of fleshing this out that draws on two different forms of virtue epistemology. ${ }^{20}$

\section{Excuses, Responsibility, and Competence}

Let's restrict discussion to the epistemic norm $\mathrm{N}$ that says, "One epistemically ought to believe that $\mathrm{p}$ if and only if one knows that $\mathrm{p}$." The derivative norm ODN, then, says that one ought to do what the kind of person who is normally disposed to believe that $p$ if and only if they know that $\mathrm{p}$ would do in a given situation. One natural idea is to think of the contents of ODN as involving the sort of character traits that responsibilist virtue epistemologists are interested in. I have in mind traits such as conscientiousness, openmindedness and the like (Zagzebski 1996; Baehr 2011). For example, "be conscientious", or "be open-minded" are plausible (albeit rough) ways of understanding the contents of a norm that tells you to do what the sort of person who is disposed to comply with our

\footnotetext{
${ }^{19}$ Perhaps one way of dealing with both sources of pressure is simply to find some normative standing other than justification or excuse. But I find it difficult to think of what such a status might be. Indeed, one significant advantage of the appeal to excuses is that this is already a very familiar normative notion. Still, identifying another normative standing altogether may be a strategy worth considering on another occasion. Thanks to an anonymous referee for this suggestion.

${ }^{20}$ An anonymous referee asks why - since I shift to virtue epistemology-I do not simply drop Williamson's terminology ("ODN") and focus on the virtues in what follows. There are three reasons. i) When I say "compliance with ODN" I simply mean, "doing what a person who is normally disposed to comply with $\mathrm{N}$ would do" (though I do develop a somewhat technical way of understanding this notion), but I also thereby emphasize the idea that this has some kind of positive normative status which is derivative from a primary norm determining justification. ii) Talking about excuses in terms of "compliance with ODN" fits nicely with my preferred picture on which justification is a matter of compliance with the norm of belief. This in turn helps me remain within a framework that can easily be applied to the epistemic norms debate, where the justification-excuse distinction is prominently debated in epistemology. I also think it jibes well with the way people think about justified $\Phi$-ing in real life, or at least when it comes to the law. That is to say, justified $\Phi$-ing in the eyes of the law is primarily a matter of complying with the law itself, not, for example, what one reasonably believes about the law (or one's actions), or the kinds of dispositional matters discussed in the present framework; these are claims I won't defend here. iii) The phrase "compliance with ODN" remains stylistically helpful.
} 
epistemic norm would do in a given situation. Moreover, it builds in a condition of nonaccidentality in a helpful way. This is because, as most—if not all—responsibilist virtue epistemologists agree, the intellectual virtues come with a motivational component. Very roughly, a character trait counts as an intellectual virtue only if it manifests the agent's motivation to achieve some sort of cognitive value (such as truth, or knowledge), in addition to being reliably successful at doing so (Zagzebski 1996; Baehr 2011; Greco 2000). If that is right, then one cannot merely happen to comply with ODN. One must also be motivated in the right sort of way. Since acting like a virtuous person on a specific occasion - for example, displaying a genuine bit of open-mindedness-is something someone who is not generally open-minded may be capable of doing, this is a promising alternative to requiring full-fledged compliance with DN in explaining how deserving an excuse is a positive (enough) normative standing. ${ }^{21}$

For those sceptical of responsibilism, note that there are promising resources in other forms of virtue epistemology as well. For example, we might say that compliance with ODN sometimes merely requires manifesting the kind of dispositions focused on by reliabilist virtue epistemologists, insofar as they make claims about "abilities" or "competences" necessary for knowledge, for example (Greco 2010; Sosa 2011; Pritchard 2012; Kelp 2013). These are innate dispositions to believe truly or to know (such as having good eyesight, or a good memory). ${ }^{22}{ }^{23}$ Doing what the kind of person who is disposed to comply with our epistemic norm $\mathrm{N}$ would do in a given situation, then, need merely be a matter of manifesting a certain set of innate abilities or competences to believe in accordance with that norm. When one manifests such abilities, despite failing to comply with our epistemic norm, one may be excused for so failing.

This proposal avoids the issue of accidental compliance with ODN, not because of any sort of motivational component, but rather because innate cognitive abilities or competences are a kind of stable disposition to get things right. If compliance with ODN amounts to manifesting a stable disposition to comply with $\mathrm{N}$, then compliance with ODN is not the sort of thing that happens by accident. This looks like a way of explaining why (at least some of) the BIV's and GETTIER victim's beliefs are excusable (for example, their basic perceptual beliefs). But interestingly, it likewise looks like a way of

\footnotetext{
${ }^{21}$ A question remains about the degree to which a generally non-open-minded person is capable of satisfying the motivational component of the intellectual virtues on a specific occasion.

${ }^{22}$ Greco (1992): "Examples of human intellectual virtues are sight, hearing, introspection, memory, deduction and induction" (p.520).

${ }^{23}$ Recently, a number of epistemologists have developed "knowledge-first" forms of virtue epistemology. According to knowledge-first epistemologists, the goal or aim of a cognitive ability is knowledge rather than true belief (Kelp forthcoming; Miracchi 2014).
} 
approaching the agents in Gerken's cases. ${ }^{24}$ After all, it is not implausible to think of small children as having such innate cognitive abilities.

In sum, I think we can explain what it is for agents to deserve an excuse in cases like GETTIER and BIV in terms of mere compliance with ODN. I claim that compliance with ODN requires manifesting cognitive virtues. Whether we focus on innate reliabilist abilities or competences, or acquired responsibilist virtues, depends on the specific belief(s) or behaviors of the BIV that are in question. Importantly, however, at a minimal level, compliance with ODN always requires the manifestation of innate cognitive abilities or competences. To this extent, our explanation extends across an interesting range of cases. That is to say, it explains why the BIV deserves an excuse, but it also explains why Gerken's small children deserve an excuse, as well as epistemic analogues of the reforming promise breaker (more in moment about the fact that the proposal does not intelligibly seem to extend to the reforming promise breaker himself). And since manifesting such cognitive abilities is a commendable or positive thing, we also account for ENE. In other words, we can explain why deserving an excuse is a positive enough normative standing in an interesting range of cases (i.e. in a principled way). To emphasize, the proposal does this by beefing up what is involved in compliance with ODN, as opposed to focusing on DN. It thereby avoids the problems of focusing on a norm that requires an agent to be a particular kind of person; but it is capable of dealing with the worries about chance compliance with ODN that motivated focusing on DN in the first place. I will briefly consider a couple of objections before concluding.

One objection is that it is not clear why this proposal does not run into the objection I put forward earlier to giving compliance with DN an important role in our theory of excuses. After all, we have discovered that an important feature of "virtue" talk is the appeal to stable dispositions. In other words, invoking abilities or competences in an account of what is involved in compliance with ODN seems automatically to entail compliance with DN. So, it seems that by understanding what it takes, for example, for the BIV to have an excuse in terms of compliance with ODN, we are still committed to claiming that the BIV must be a particular kind of person. As the argument above showed, this sort of explanation of what goes on when an agent deserves an excuse is disconcertingly limited.

Here is a response. Requiring that an agent satisfy certain global or general conditions on their innate cognitive abilities or competences does not unduly or problematically limit an account of epistemic excuse. For an agent to deserve an epistemic excuse in any given situation, it is plausible that they do need to have dispositions in the way implied by the notion of cognitive abilities or competences. In other words, the kind of person we are

\footnotetext{
${ }^{24}$ To be sure, Gerken uses his cases in a discussion of the knowledge norm of action. But I take translation into a discussion of the knowledge norm of belief to be straightforward in the present context.
} 
committed to claiming the BIV must be, in order to be in the market for deserving an excuse, is a minimal enough sort of thing that it features (at least partially, and perhaps implicitly) in a quite general sort of explanation of why agents deserve epistemic excuses. $^{25}$

Another objection, however, is that this merely highlights a deeper worry for the present proposal. Notice that framing a theory of excuses within a reliabilist framework seems to render the theory quite specific to epistemology. It is difficult to imagine moral analogues of reliabilist virtues. Indeed, some epistemologists have claimed that reliabilist virtue epistemology is about virtues in a rather nominal sense. ${ }^{26}$ But if that is right, then, while the framework we have ended up with may provide the most general sort of explanation of epistemic excuses, the appeal to excuses in epistemology no longer seems to fall out of a general explanation of the justification-excuse distinction spanning both ethics and epistemology. Perhaps this is asking too much in the first place (more on this right away). However, it might seem unfortunate given that the Derivative Norms Framework's ability to provide such a general explanation, which is then applicable to epistemology, is one of its most interesting features. ${ }^{27}$

I have two things to say in response. First, recall that we have resources from both reliabilist and responsibilist virtue epistemology. While it is a minimal condition on deserving an excuse in the epistemic domain that one is generally reliable, it is also often going to be the case that one deserves an epistemic excuse because one exhibits some responsibilist virtue or another. To this extent, the Derivative Norms Framework will often be extendable to moral analogues of epistemic cases. To be sure, there may be some

\footnotetext{
${ }^{25}$ Littlejohn contrasts excuse with exemption in terms that are relevantly similar here (Littlejohn forthcoming, p.10). To roughly summarize, his main claim in motivating the distinction between exemptions and excuses is that excuses are normative standings that require agents to be reasonsresponsive in such a way that they can be held accountable for what they do in general (Littlejohn forthcoming, p.11). When an agent is excused with respect to the violation of some norm, this is in part because they have the relevant capacities needed for being held accountable - it is just that certain other circumstances mitigate blame (for example, non-culpable ignorance, or lack of control). Meanwhile, this is not the case when we exempt someone. Agents exempt with respect to some norm are not reasonsresponsive such that they can be held accountable for what they do in general. To put it metaphorically, they are not in the market for accountability, in a global sort of way.

${ }^{26}$ Zagzebski (1996) discusses this point in detail. For example, picking on Greco, but referring to a feature of his view shared by Sosa and other reliabilist virtue epistemologists, she says: "The sense in which Greco's examples can be considered virtues [...] is misapplied if it is intended to reflect the way the concept of virtue has been used in ethics. In fact, it has little connection with the history of the concept of intellectual virtue, although that history is quite sparse [...]. Aristotle's examples of intellectual virtues include theoretical wisdom (sophia), practical wisdom (phronesis), and understanding or insight (nous). Hobbes's list includes good wit and discretion; Spinoza's primary intellectual virtue is understanding. [...]. None of these qualities are faculties like sight or hearing" (Zagzebski 1996, p.11). I do not think the matter is so simple. I will have more to say about this below.

${ }^{27}$ Consider again, and to quote Williamson: "This essay steps back from the epistemological issues to make some of those general normative distinctions, then returns with them to epistemology" (p.3).
} 
cases in which the explanation is unique to epistemology (perhaps Gerken's small children case is an example). However, I will simply bite the bullet here. We should not expect a complete symmetry between the domain of epistemic normativity and any other domain of normativity.

Now, one might object that bringing responsibilism back into the picture at this point raises the ad hocery worry all over again. The second thing I want to say here, then, is that I don't think it should. To see why, consider that while reliabilist and responsibilist epistemology are, on the face of it, very different approaches to epistemology, the differences should not be exaggerated. Indeed, an appeal to one goes naturally with an appeal to the other. Let me explain. ${ }^{28}$

According to Jason Baehr, "the very distinction between virtue reliabilism and virtue responsibilism is considerably more sketchy than it initially appears" (IEP, "Virtue Epistemology"). For instance, Baehr claims that while reliabilist virtue theory is primarily interested in truth conduciveness - thus making good sense of its focus on cognitive faculties like vision and memory - it must be noted that our epistemic goals in actual human life (goals such as scientific discoveries, for example) require more than the reliable functioning of cognitive faculties like vision and memory. They seem to require certain virtuous character traits, like open-mindedness, intellectual courage, and the like (one might disagree about whether this is necessarily true; but as a matter of contingent fact, such traits certainly don't seem to hurt the progress of science). Baehr claims:

[T] he most plausible version of virtue reliabilism will incorporate many [responsibilist] traits into its repertoire of virtues and in doing so will go significant lengths toward bridging the gap between virtue reliabilism and virtue responsibilism (IEP, "Virtue Epistemology").

Getting into the precise details of what Baehr has in mind would take us too far afield. But note that some of the most prominent virtue reliabilists seem to agree with the general idea. For example, here is Sosa stating the primary aim of his (2015) Judgment and Agency: "I will offer a better responsibilist account, one that welcomes responsibilism at the core of virtue reliabilism" (Sosa 2015, p.35). Of course precisely what Sosa agrees with Baehr about is a subtle issue. For example, one of Sosa's key tenets is that, contrary to objections from many responsibilist virtue epistemologists, a responsibilist component has always been incorporated within reliabilist virtue epistemology (Sosa 2015, p.35). Also, his precise way of "welcoming responsibilism at the core of virtue reliabilism" goes via a claim, first, that we should recognize a kind of "active, volitional virtue" that is a "special case of reliable competence intellectual

\footnotetext{
${ }^{28}$ Thanks to an anonymous referee for pressing the ad hocery worry.
} 
virtue", and, second, that we should understand responsibilist virtues as "auxiliary to the special case of reliable-competence intellectual virtue" (Sosa 2015, p. 35-36). Again, the details would take us too far afield. For now, suffice it to say that-however the details get fleshed out - the most prominent virtue reliabilists are interested in making an important place for responsibilism within a reliabilist framework. ${ }^{29}$

I agree with Sosa and Baehr that a complete virtue epistemology would incorporate elements from both camps, rather than focus heavily on their differences. These are reasons that an appeal to one kind of virtue epistemology goes naturally with an appeal to the other-reasons that have nothing special to do with the present context. So pointing out that we have resources from both camps is not an ad hoc way of defending the Derivate Norms Framework. Indeed, I think the fact that it helps the Framework is one more reason to see the two camps as fitting naturally together.

\section{Conclusion}

I have argued for a number of points in this paper, so let's take stock. First, I explained how the Derivative Norms Framework inspires a way to advance debate beyond Gerken's objection to the so-called "excuse maneuver". Next I raised the objection that excuse defenses are too weak or negative sounding in certain important cases. Dealing with this issue generates pressure in two directions. The first source of pressure is making excuses seem like a positive enough defense. The second source of pressure is filling that story out in a way that seems general and principled enough to avoid rekindling Gerken-style worries about ad hocery. Finally, I turned to a positive proposal. I argued that we should fill the Derivative Norms Framework out with resources from two kinds of virtue epistemology. In particular, I claimed that we should understand compliance with ODN in terms of the manifestation of cognitive virtues. The result is a view about the nature of epistemic excuses that can deal with both sources of pressure.

The aim of this paper has not been to defend strong externalism over all other views about epistemic justification. Rather, the aim has been to examine the motivation for the strong externalist's appeal to excuses. Does it merely help the strong externalist deal with some problematic cases? Or does it latch onto an independently motivated conception of

\footnotetext{
${ }^{29}$ Note, too, that there is room to challenge the position - mentioned briefly above - that reliabilist virtue theory is a virtue theory in name only. For example, by appealing to lesser known but no less historically important usages of "virtue" (for example in Plato and Aquinas) ${ }^{29}$ Greco (2000) argues that one cannot settle the question of the correct or fundamental usage of "virtue" simply by deferring to Aristotle (he claims Zagzebski's objection to the reliabilist usage of "virtue" hinges on this): "If we do not make Aristotle's account of moral virtue definitional of the concept of virtue in general, then we can see that Sosa, Goldman and Zagzebski are members of an important camp; one appropriately labeled 'virtue epistemology"' (Greco 2000, p.181).
} 
the structure of epistemic normativity? I have argued in support of the latter. Perhaps surprisingly, virtue epistemology provides resources for explaining how agents can be excused for holding unjustified beliefs, depending on whether they comply with the relevant derivative norms.

\section{References}

Adler, J. 2002. Belief's Own Ethics. MIT Press: Cambridge.

Arpaly, N. 2002. Unprincipled Virtue: An Inquiry Into Moral Agency. OUP: Oxford.

Baehr, J. 2011. The Inquiring Mind. OUP: Oxford.

Virtue epistemology. Internet Encyclopedia of Philosophy.

Bonjour, L. 2002. Internalism and Externalism. In Moser, P. (ed.) The Oxford Handbook of Epistemology. OUP: Oxford.

Burge, T. 2003. Perceptual entitlement. Philosophy and Phenomenological Research 67: 503-48.

Cohen, S. and Comesaña, J. 2013. Williamson on Gettier cases and epistemic logic.

Inquiry 56: 15-29.

DeRose, K. 2002. Assertion, Knowledge, and Context. Philosophical Review 111:167203.

Dretske, F. 1981. Knowledge and the Flow of Information. MIT Press: Cambridge, MA.

Gerken, M. 2011. Warrant and action. Synthese 178: 529-47.

2012. Discursive justification and skepticism. Synthese 189: 373-394.

Graham, P. 2012. Epistemic entitlement. Nous, 46:449-483.

Greco, J. 2010. Achieving Knowledge. CUP: Cambridge.

2000. Two kinds of intellectual virtue. Philosophy and Phenomenological Research. 60:1.

Goldman, A. 1988. Strong and weak justification. Philosophical Perspectives 2:51-69. 1979. What is justified belief? In Justification and Knowledge, ed. G.S Pappas. Reidl: Dordrecht.

Kelp, C. 2013. Knowledge: the safe-apt view. Australasian Journal of Philosophy 91: 265-278. 
forthcoming. Knowledge first virtue epistemology. In Carter, A., Gordon, E., and Jarvis, B., (eds.) Knowledge First: Approaches in Epistemology and Mind. OUP: Oxford.

Huemer, M. 2007. Moore's Paradox and the Norm of Belief. In, Nuccetelli, S. and Seay, G. (eds.), Themes from G.E Moore: New Essays in Epistemology and Ethics. Clarendon Press.

Lackey, J. 2007. Norms of assertion. Nous 41: 594-626.

Littlejohn, C. forthcoming. A plea for epistemic excuses. In, F. Dorsch and J. Dutant (eds.), The New Evil Demon. OUP: Oxford.

Madison, B.J.C. 2014. Epistemological Disjunctivism and the New Evil Demon. Acta Analytica 29: 61-70.

Mirracchi, L. 2014. Competence to know. Philosophical Studies 172: 29-56.

Pritchard, D. 2012. Anti-luck virtue epistemology. Journal of Philosophy 109: 247-279.

Sosa, E. 2011. Knowing Full Well. Princeton University Press. 2015. Judgment and Agency. OUP: Oxford

Sutton, J. 2007. Without Justification. MIT Press: Cambridge.

Williamson, T. forthcoming. Justifications, excuses, and sceptical scenarios. In, F. Dorsch and J. Dutant (eds.), The New Evil Demon. OUP: Oxford. 2013. Getter cases in epistemic logic. Inquiry 56: 1-14. 2000. Knowledge and Its Limits. OUP: Oxford.

Zagzebski, L. 1996. Virtues of the Mind. CUP: Cambridge. 